\title{
Ghrelin and leptin levels in relation to puberty and reproductive function in patients with beta-thalassemia
}

\author{
Ghollam-Reza Moshtaghi-Kashanian¹, Fakhrolmulok Razavi² \\ ${ }^{1}$ Physiology Research Center, Kerman University of Medical Sciences, ${ }^{2}$ Biochemistry Department, Medical School, \\ Kerman University of Medical Sciences, Kerman, Iran
}

\begin{abstract}
OBJECTIVE: Recently published animal studies indicate that leptin and ghrelin play a role in puberty initiation and progress as well as in reproduction. The aim of our study was to evaluate the relation of these two hormones to the pubertal maturity and fertility status in patients with $\beta$-thalassemia. DESIGN: Blood levels of leptin, acylated ghrelin and sex hormones were determined in 97 ( 59 males and 38 females) beta-thalassemic patients, aged 18-23 years and in 50 healthy subjects (27 males and 23 females) matched for age. Body Mass Index (BMI) was also assessed. RESULTS: Besides lower BMI, all the hormones evaluated were significantly lower in $\beta$-thalassemic patients compared to controls $(p<0.001)$. Furthermore, the leptin/ghrelin ratio in female patients was lower than the values obtained in the controls $(p<0.001)$. Finally, significant negative correlations $(p=0.050)$ were detected between circulating levels of acylatedghrelin and LH, FSH and sex hormones in female and male patients. CONCLUSIONS: The lower values of leptin and ghrelin in patients with $\beta$-thalassemia possibly constitute another hormonal imbalance which may contribute to the phenotype of impaired growth and sexual maturation encountered in these patients. The findings on the ghrelin levels constitute a novel observation.
\end{abstract}

Key words: Acylated-ghrelin, Beta-thalassemia, Fertility, Leptin, Puberty, Reproductive hormones

\section{INTRODUCTION}

Following the application of desferrioxamine (desferal) as an effective iron chelator, survival of patients with $\beta$-thalassemia has significantly improved. However, due to its large molecular size, desferal

Address for correspondence:

Ghollam-Reza Moshtaghi-Kashanian, Associate Professor of

Pathological Biochemistry,

Tel: +98 3412456207 , Fax: +983412454968

E-mail: MoshtaghiKashanian@hotmail.com

Received 24-10-08, Revised 05-04-09, Accepted 10-05-09 permeability into the cells is relatively slow and its efficacy as an intracellular iron chelator is limited. ${ }^{1}$ This is why many transfusion dependent homozygote beta-thalassemic patients continue to develop progressive accumulation of iron overload despite the fact that they use desferal regularly. Gradual increase of iron deposition in different organs could be responsible for tissue damage and a number of complications including impaired growth and puberty delay in these patients. ${ }^{2-5}$

Pubertal development and fertility are determined 
by a multi-hormonal effect. A functional defect in any of the components of this hormonal complex directly affects puberty and reproduction in either gender. Recent research added two new members to this hormonal complex, namely leptin and ghrelin, ${ }^{6-11}$ hormones secreted by adipose tissue and the gastrointestinal tract, respectively. Besides their effect on carbohydrate and fat metabolism and appetite, these hormones acting on the hypothalamic-pituitarygonadal axis, exert various effects on reproductive function, implantation, embryo development, and clinically relevant conditions. ${ }^{6}$

Leptin is produced by adipocytes and is closely related to the feeding state in different animals. Stimulation of reproductive neuroendocrine output is also associated with increased circulating levels of leptin. ${ }^{12}$ This hormone primarily acts on the hypothalamus and its deficiency in the ob/ob mouse results in persistent immaturity as a result of hypothalamic-pituitary malfunction. ${ }^{13}$ To our knowledge, several studies have been published on leptin levels in different age groups of thalassemic patients ${ }^{14-16}$ and in all of them low leptin levels were observed, with variable conclusions being reached depending on the study design and the patient cohort.

Ghrelin is the endogenous ligand of the growth hormone $(\mathrm{GH})$ secretagogue receptor and has been implicated in the regulation of a large array of endocrine and non-endocrine functions, including the control of GH secretion, food intake, energy balance and control of adipocity. ${ }^{17}$ Despite the proven link between energy homeostasis and fertility, the potential role of ghrelin in the control of gonadal function in thalassemic patients has not been assessed. To achieve this goal, we searched for the interconnections between ghrelin or leptin and reproductive hormones at the various developmental stages. Blood levels of leptin, acylated-ghrelin (active form) follicle stimulating hormone (FSH), luteinizing hormone $(\mathrm{LH})$, progesterone, testosterone and estradiol were determined in homozygote beta-thalassemic patients regularly attending the special thalassemic clinic in the city of Kerman (Iran), and in controls.

\section{SUBJECTS AND METHODS:}

The Ethics Committee of Kerman University ap- proved the protocol of this study, which is in accordance with the internationally accepted principles as found in the European Community guidelines (EEC Directive of 1986; 86/609/EEC) and the US guidelines (NIH publication \#85-23, revised in 1985). Ninetyeight homozygote beta-thalassemic patients, aged 18-23 years attending the special clinic participated in this study. In these patients the diagnosis of betathalassemia major had been made at the age of 4-12 months and since that time they have been receiving packed red blood cell transfusions regularly. The number of blood pack cells transfusion received ranged from 20-50 packs per year depending on the severity of the anemia and their age. The average amount of desferrioxamine used was $10-40$ vials $(500 \mathrm{mg}$ ) per week, depending on the blood volume they received to maintain a hemoglobin level of $12 \mathrm{~g} / \mathrm{dl}$. Fifty-nine of these patients were males with impaired sexual development and 38 were females with irregular menses or amenorrhea. Fifty healthy college students, aged 18-23 years (27 males and 23 females) matched for age and gender were used as controls

All male participants were requested to come fasting for sample collection in order to have a uniform sampling of the levels of reproductive hormones. Females in the control group were asked to come fasting within the third week past their menses. Since female patients had irregular menses or were suffering from amenorrhea, samples were collected either before their routine blood transfusion or within the third week past their last menses.

Five $\mathrm{ml}$ of fasting blood were collected and divided into two tubes to prepare plasma for measurement of acylated-ghrelin using EDTA as anticoagulant ${ }^{18}$ and serum for evaluation of other hormones. Samples were centrifuged at $800 \mathrm{~g}$ for 5 minutes and plasma or serum was kept at $-70^{\circ}$ till the time of assay. Serum levels of gonadotropins (FSH and $\mathrm{LH}$ ) and ferritin were determined in all participants using Elisa kits manufactured by Monobind Industry (Lake Forest, CA, USA). Serum levels of steroid hormones (progesterone, testosterone and estradiol) were also determined in all samples using Elisa kits purchased from IBL, Germany. For leptin determination, we used the Elisa kit manufactured by DBC Diagnostic Biochem (Canada). Plasma acylated-ghrelin was determined using the Elisa kit from BioVendor Labo- 
ratory Medicine Industry (Czech Republic). For all hormones the standard protocols provided by the manufacturers were followed.

Data were analyzed using the SPSS (Version 14.0) program. The independent sample t-test was used for comparison of the two groups after checking for normal distribution of the data. For multiple comparisons of circulating acylated-ghrelin and leptin of the four groups, one-way ANOVA (post Hoc Tukey's model) was used. Determination of correlations was carried out using Pearson's two-tailed bivariate model. $\mathrm{p}$-values less than 0.05 were considered as significant differences.

\section{RESULTS}

The patients and control subjects were divided into two groups according to their gender. Height, weight and BMI of patients were significantly $(\mathrm{p}<0.001)$ lower than their respective values in the control group. Furthermore, as was expected, serum ferritin levels of all patients were significantly higher than those of the healthy participants $(\mathrm{p}<0.001)$.

Mean circulating FSH levels in healthy male controls were higher than $\mathrm{LH}$, while circulating levels of LH and FSH in male patients were comparable. Both LH and FSH of male patients were significantly lower $(\mathrm{p}<0.001)$ than the corresponding values in the controls. Mean values of LH and FSH in female patients were also significantly lower $(\mathrm{P}<0.001)$ than the corresponding values obtained in the female controls.

The values of steroid hormones progesterone, testosterone and estradiol in patients were also significantly lower than the corresponding values in the controls $(\mathrm{p}<0.001)$. The values of leptin and acylated-ghrelin were significantly lower than the values obtained in the corresponding healthy controls $(\mathrm{p}<0.001)$.

To determine correlations between leptin or ghrelin and each of reproductive hormones, Pearson's two-tailed bivariate correlation analysis was carried out for each group. The results showed distinct and significant $(\mathrm{p}<0.050)$ negative correlations between acylated-ghrelin and $\mathrm{LH}(\mathrm{r}=-0.40), \mathrm{FSH}(\mathrm{r}=-0.39)$, estradiol $(r=-0.30)$ or testosterone $(r=-0.28)$ for the male patients, while these correlations were not observed in the other three groups (Figures 1 and 2). The ratio of leptin/acylated-ghrelin values were lower $(\mathrm{p}<0.001)$ in the female patients compared with the healthy females (Table 1).

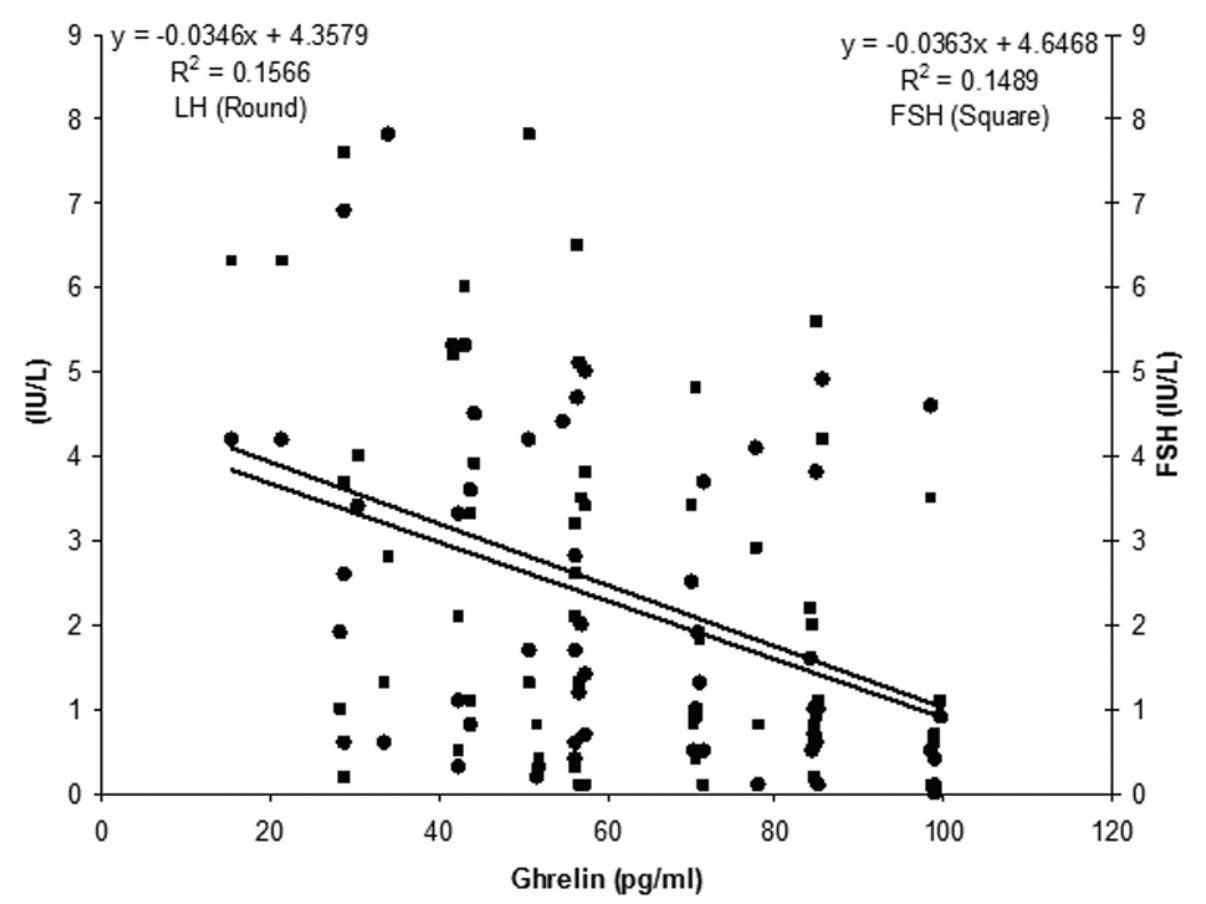

Figure 1. Negative correlation between ghrelin and LH or FSH in male homozygote beta-thalassemic patients $(\mathrm{p}<0.001)$. 


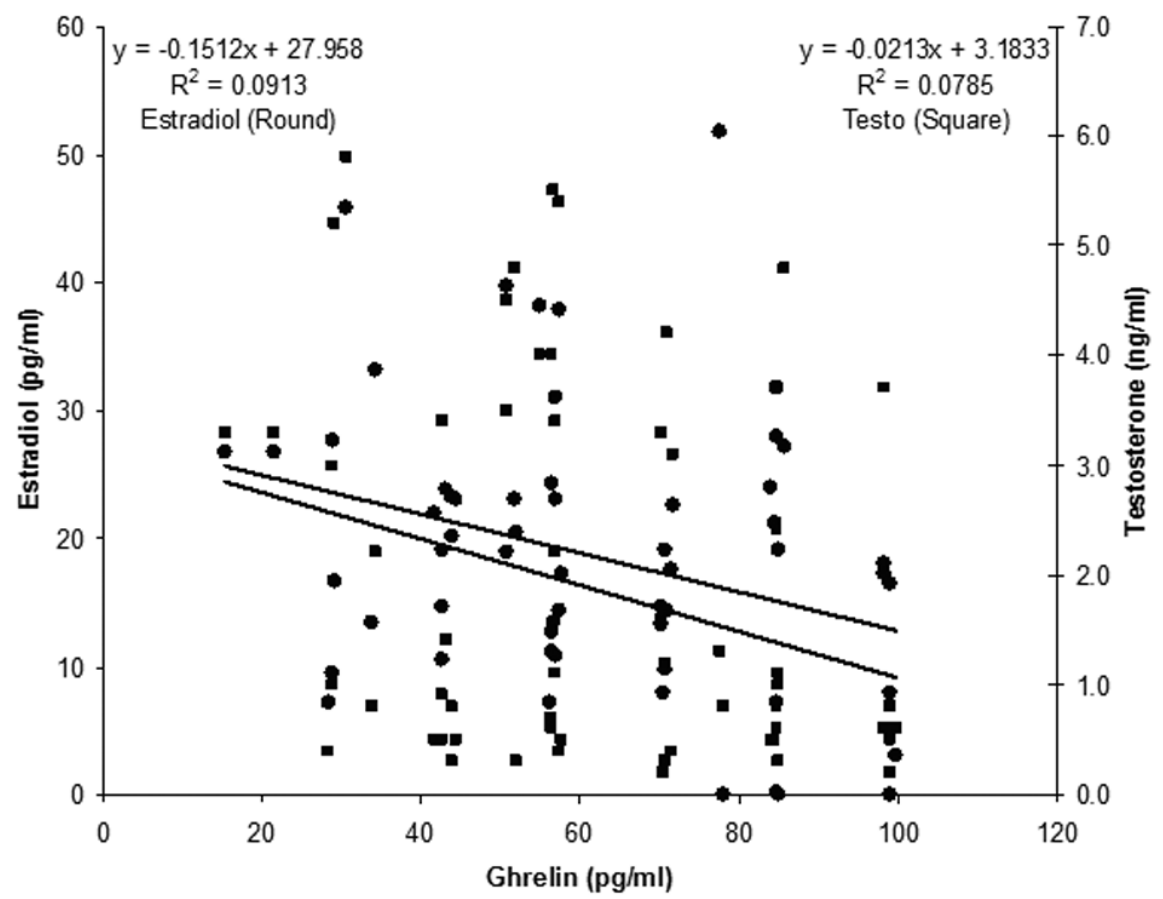

Figure 2. Negative correlation between ghrelin and estradiol or testosterone in male homozygote beta-thalassemic patients $(\mathrm{P}<0.001)$. To convert to SI units multiply by 3,671 for estradiol and 3,467 for testosterone.

Table 1. Various parameters in the two groups (patients vs controls) by gender. Data presented as mean (SD)

\begin{tabular}{|c|c|c|c|c|}
\hline Parameters & $\begin{array}{l}\text { Male Patients } \\
\quad(\mathrm{N}=59)\end{array}$ & $\begin{array}{l}\text { Male Controls } \\
\quad(\mathrm{N}=\mathbf{2 7})\end{array}$ & $\begin{array}{l}\text { Female Patients } \\
\quad(\mathbf{N}=\mathbf{3 8})\end{array}$ & $\begin{array}{c}\text { Female Controls } \\
\quad(\mathrm{N}=23)\end{array}$ \\
\hline Age (years) & $20.05(1.93)$ & $19.78(1.72)$ & $20.34(2.02)$ & $19.96(1.61)$ \\
\hline Weight (kg) & $44.32(9.38)$ & $67.67(9.28) *$ & $46.86(7.80)$ & $55.61(7.04) *$ \\
\hline Height (cm) & $149.9(9.55)$ & $171.74(7.05)^{*}$ & $150.5(7.81)$ & $160.30(6.65) *$ \\
\hline BMI (kg/m2) & $19.54(2.56)$ & $22.96(2.92)^{*}$ & $20.56(2.28)$ & $21.71(3.05)^{*}$ \\
\hline Ferritin (ng/ml) & $4196(2402)$ & $38.89(22.96) *$ & 4907 (1881) & $23.16(8.15)^{*}$ \\
\hline LH (IU/L) & $2.22(1.96)$ & $4.15(1.91)^{*}$ & $4.27(2.53)$ & $5.94(1.87)^{*}$ \\
\hline FSH (IU/L) & $2.40(2.11)$ & $7.43(2.96) *$ & $3.51(2.60)$ & $10.47(3.91) *$ \\
\hline \multirow[t]{2}{*}{ Progesterone (nmol/L) } & $0.64(0.45)$ & $0.95(0.57)^{*}$ & $3.85(5.11)$ & $19.30(10.78)^{*}$ \\
\hline & $0.20(0.14)$ & $0.30(0.18)$ & $1.21(1.67)$ & $6.07(3.39)$ \\
\hline \multirow[t]{2}{*}{ Testosterone (nmol/L) } & $6.49(5.90)$ & $19.09(5.17)^{*}$ & $1.46(0.62)$ & $2.53(0.97)^{*}$ \\
\hline & $1.87(1.70)$ & $5.50(1.49)$ & $0.42(0.18)$ & $0.73(0.28)$ \\
\hline \multirow[t]{2}{*}{ Estradiol (nmol/L) } & $68.30(41.10)$ & $107.79(37.21)^{*}$ & \multirow{2}{*}{$\begin{array}{c}120.93 \text { (77.14) } 32.95 \\
(21.02)\end{array}$} & $270.11(87.64)^{*}$ \\
\hline & $18.61(11.20)$ & $29.37(10.14)$ & & $73.60(23.88)$ \\
\hline Leptin (ng/ml) & $2.40(2.28)$ & $4.30(1.99) *$ & $4.39(1.95)$ & $17.30(5.60) *$ \\
\hline$\alpha$ Ghrelin $(\mathrm{pg} / \mathrm{ml})$ & $61.78(22.37)$ & $87.91(42.44) *$ & $80.73(29.10)$ & $142.68(43.25)^{*}$ \\
\hline Ratio of Leptin/ $\alpha$ - Ghrelin & $44.21(45.23)$ & $58.07(33.11)$ & $62.39(36.84)$ & $131.90(60.97)^{*}$ \\
\hline
\end{tabular}

* Significant differences $(\mathrm{p}<0.05)$ between patients and gender matched controls. N: number of participants in each group, $\alpha$ ghrelin: acylated-ghrelin. 


\section{DISCUSSION}

Puberty constitutes a distinct developmental stage characterized by physiological, anatomical and psychological alterations and comprises a preparatory step for reproduction. Age at puberty is determined by genetic and environmental factors. Delayed puberty in thalassemic patients has previously been reported. ${ }^{19-21}$ The patients in the present study were pubertal (18-23 years old). All female patients had their menarche, but they were suffering from secondary amenorrhea or irregular menses at the time of sample collection, while male patients were suffering from impotence or did not have the secondary characteristics fully developed.

It has been suggested that low circulating levels of $\mathrm{LH}$ and FSH among thalassemic patients is the result of impaired GnRH secretion resulting in inadequate pituitary stimulation. ${ }^{21,22}$ This could be the reason for the detection of low levels of gonadotropins resulting in low circulating levels of gonadal steroids in our patients.

Recently published results from animal studies showed that both leptin and ghrelin have a role in $\mathrm{GnRH}$ production at different reproductive stages. ${ }^{7,9,13,24-27}$ Additionally, leptin and ghrelin showed opposing effects on pulsatile GnRH secretion. ${ }^{9}$ Furthermore, obese children have early puberty that could be the effect of high circulating levels of leptin. ${ }^{28-31}$ Low levels of circulating leptin could be one of the reasons for delayed puberty among patients with $\beta$ thalassemia, particularly among the male patients who have lower leptin levels than female patients.

Expression of ghrelin has been demonstrated in mature Leydig cells of rat and human testis, as well as in steroidogenically active luteal and interstitial hilus cells of the ovary. ${ }^{26}$ Gonadal expression of acylated-ghrelin receptors was also shown in Sertoli and Leydig cells of the testis and in follicular, luteal, surface epithelial and interstitial hilus cells of the ovary. ${ }^{26}$ Vulliemoz et $\mathrm{al}^{24}$ showed that ghrelin can inhibit GnRH pulse activity in ovariectomized adult monkey, while Lebrethon et $\mathrm{al}^{9}$ reported that ghrelin reduces $\mathrm{GnRH}$ in the pre-pubertal period in male rats and has no effect in mature rats. Fernandez-Fernandez et $\mathrm{al}_{,}{ }^{27,32}$ who have investigated the role of ghrelin on sexual maturation, showed that ghrelin inhibits LH secretion in vivo in the pre-pubertal males as well as gonadectomized male and female rats, whereas FSH remained unaffected. Tena-Sempere ${ }^{17,33}$ also showed that ghrelin could reduce circulating steroid hormones in pre-pubertal male rats.

Our results indicating that circulating acylatedghrelin in thalassemic patients (both sexes) are significantly lower than in healthy individuals constitute a novel observation. According to data obtained from studies in rodent and higher animals, the levels of gonadotropins would be expected to be high in our patients who have low levels of circulating ghrelin, which was not the case. The interpretation is not apparent. However, we found negative and significant parallel correlations between ghrelin and LH, FSH, testosterone and estradiol in male patients, data resembling those obtained in the rodent studies. ${ }^{17,27,32,33} \mathrm{We}$ also evaluated the ratio of leptin to ghrelin in the four groups of participants. This set of data showed that the leptin/ghrelin ratio of patients (both genders) was lower than in the respective control group. The excess of ghrelin in respect to leptin could be the cause of the negative correlation observed between ghrelin and gonadotropins or steroid hormones in male patients. Furthermore, these data also indicate that a balance between leptin and ghrelin is essential for appropriate puberty timing, a fact that was documented before the discovery of these hormones. ${ }^{34}$

A positive correlation between leptin and BMI was detected only in the female control group, a finding in agreement with previous reports. ${ }^{35}$ Since the BMI of the patients is lower than that of the gender matched control group, it could be concluded that adipose tissue is unable to maintain adequate leptin production when a higher leptin secretion is required, suggesting that the inappropriately low leptin secretion or decreased leptin/ghrelin ratio could contribute to the relevant pathology, namely the irregular menses or amenorrhea of the thalassemic females. Obviously, more data are needed for a valid interpretation of our findings, which may have relevance to other forms of irregular menses or amenorrhea.

In conclusion, the balance of reproductive hormones in homozygous beta-thalassemic patients is impaired. Low circulating levels of LH and FSH as well as of steroid hormones in both sexes are detected. 
The reduced levels of reproductive hormones in $\beta$ thalassemic patients could be the result of intercellular iron overload and/or disturbance of the immune system. ${ }^{35}$ Nevertheless, leptin and ghrelin values could also play a role in sexual maturity and fertility problems observed in these patients. We hypothesize that a decreased leptin/acylated-ghrelin ratio may also constitute one of the mechanisms involved in delayed puberty, irregular menses or amenorrhea not only in beta-thalassemic patients but also in nonthalassemic subjects.

\section{ACKNOWLEDGEMENT}

The authors express their deep appreciation to the participants of the present study, without whose contribution this research could not have been carried out. We also thank the Doctors and staff of the Special Hematological Clinic (Kerman, Iran) who provided us with data and samples of the patients. The funding of this study was provided by the research deputy of Kerman University of Medical Sciences, Kerman, Iran (85/99).

\section{REFERENCES}

1. Breuer W, Ermers MJ, Pootrakul P, Abramov A, Hershko C, Cabantchik ZI, 2001 Desferrioxamine-chelatable iron, a component of serum non-transferrin-bound iron, used for assessing chelation therapy. Blood 97: 792-798.

2. Papadimas J, Goulis DG, Mandala E, et al, 2002 Betathalassemia and gonadal axis: a cross sectional, clinical study in a Greek population. Hormones (Athens) 1: 179-187.

3. Low LC, 1997 Growth, puberty and endocrine function in beta-thalassaemia major. J Pediatr Endocrinol Metab 10: 175-184.

4. Raiola G, Galati MC, De Sanctis V, et al, 2003 Growth and puberty in thalassemia major. J Pediatr Endocrinol Metab 16: Suppl 2: 259-266.

5. Moshtaghi-Kashanian GR, Ahmadi A, Hayatbakhsh MM, 2004 The role of parathyroid hormone on stature in major beta thalassemic patiens (Persian Article). Journal of Rafsanjan University of Medical Sciences 3: 258-265.

6. Budak E, Fernandez Sanchez M, Bellver J, et al, 2006 Interactions of the hormones leptin, ghrelin, adiponectin, resistin, and PYY3-36 with the reproductive system. Fertil Steril 85: 1563-1581.

7. Akhter N, Johnson BW, Crane C, et al, 2007 Anterior pituitary leptin expression changes in different reproductive states: in vitro stimulation by gonadotropin-releasing hormone. J Histochem Cytochem 55: 151-166.

8. De Placido G, Alviggi C, Clarizia R, et al, 2006 Intrafollicular leptin concentration as a predictive factor for in vitro oocyte fertilization in assisted reproductive techniques. J Endocrinol Invest 29: 719-726.

9. Lebrethon MC, Aganina A, Fournier M, Gérard A, Parent AS, Bourguignon JP, 2007 Effects of in vivo and in vitro administration of ghrelin, leptin and neuropeptide mediators on pulsatile gonadotrophin-releasing hormone secretion from male rat hypothalamus before and after puberty. J Neuroendocrinol 19: 181-188.

10. Kiess W, Blum WF, Aubert ML, 1998 Leptin, puberty and reproductive function: lessons from animal studies and observations in humans. Eur J Endocrinol 138: 2629.

11. Miller DW, Harrison JL, Brown YA, et al, 2005 Immunohistochemical evidence for an endocrine/paracrine role for ghrelin in the reproductive tissues of sheep. Reprod Biol Endocrinol 3: 60.

12. Adam CL, Archer ZA, Miller DW, 2003 Leptin actions on the reproductive neuroendocrine axis in sheep. Reprod Suppl 61: 283-297.

13. Smith GD, Jackson LM, Foster DL, 2002 Leptin regulation of reproductive function and fertility. Theriogenology 57: 73-86.

14. Dedoussis GV, Kyrtsonis MC, Andrikopoulos NE, Voskaridou E, Loutradis A, 2002 Inverse correlation of plasma leptin and soluble transferrin receptor levels in beta-thalassemia patients. Ann Hematol 81: 543-547.

15. Karachaliou F, Vlachopapadopoulou E, Theochari M, Konstandellou E, Michalados S, 2006 Leptin levels in patients with thalassemia major. Minerva Pediatr 58: 373-378.

16. Perrone L, Perrotta S, Raimondo P, et al, 2003 Inappropriate leptin secretion in thalassemia: a potential cofactor of pubertal timing derangement. J Pediatr Endocrinol Metab 16: 877-881.

17. Tena-Sempere M, 2005 Ghrelin: novel regulator of gonadal function. J Endocrinol Invest 28: 26-29.

18. Hosoda H, Doi K, Nagaya N, et al, 2004 Optimum collection and storage conditions for ghrelin measurements: octanoyl modification of ghrelin is rapidly hydrolyzed to desacyl ghrelin in blood samples. Clin Chem 50: 10771080.

19. Moayeri H, Oloomi Z, 2006 Prevalence of growth and puberty failure with respect to growth hormone and gonadotropins secretion in beta-thalassemia major. Arch Iran Med 9: 329-334.

20. Soliman AT, Nasr I, Thabet A, Rizk MM, El Matary W, 2005 Human chorionic gonadotropin therapy in adolescent boys with constitutional delayed puberty vs those with beta-thalassemia major. Metabolism 54: 15-23.

21. Saka N, Sukur M, Bundak R, et al, 1995 Growth and puberty in thalassemia major. J Pediatr Endocrinol Metab 8:181-186.

22. Valenti S, Giusti M, McGuinness D, et al, 1995 Delayed 
puberty in males with beta-thalassemia major: pulsatile gonadotropin-releasing hormone administration induces changes in gonadotropin isoform profiles and an increase in sex steroids. Eur J Endocrinol 133: 48-56.

23. Danesi L, Scacchi M, Miragoli AM, et al, 1994 Induction of follicle maturation and ovulation by gonadotropin administration in women with beta-thalassemia. Eur $\mathbf{J}$ Endocrinol 131: 602-606.

24. Vulliemoz NR, Xiao E, Xia-Zhang L, et al, 2004 Decrease in luteinizing hormone pulse frequency during a five-hour peripheral ghrelin infusion in the ovariectomized rhesus monkey. J Clin Endocrinol Metab 89: 5718-5723.

25. Ponzo OJ, Reynoso R, Rimoldi G, et al, 2005 Leptin stimulates the reproductive male axis in rats during sexual maturation by acting on hypothalamic excitatory amino acids. Exp Clin Endocrinol Diabetes 113: 135-138.

26. Fernandez-Fernandez R, Tena-Sempere M, Roa J, et al, 2007 Direct stimulatory effect of ghrelin on pituitary release of LH through a nitric oxide-dependent mechanism that is modulated by estrogen. Reproduction 133: 1223-1232.

27. Fernandez-Fernandez R, Tena-Sempere M, Navarro VM, et al, 2005 Effects of ghrelin upon gonadotropin-releasing hormone and gonadotropin secretion in adult female rats: in vivo and in vitro studies. Neuroendocrinology 82: 245-255.

28. Himes JH, 2006 Examining the evidence for recent secular changes in the timing of puberty in US children in light of increases in the prevalence of obesity. Mol
Cell Endocrinol 254-255:13-21.

29. Biro FM, Khoury P, Morrison JA, 2006 Influence of obesity on timing of puberty. Int J Androl. 29:272-277; discussion 286-290.

30. Dunger DB, Ahmed ML, Ong KK, 2005 Effects of obesity on growth and puberty. Best Pract Res Clin Endocrinol Metab 19:375-390.

31. Cetkovic A, Djurovic M, Milic N, 2006 [Leptin and inhibin $\mathrm{B}$ as predictors of reproductive recovery in patients with anorexia nervosa during weight gain]. Srp Arh Celok Lek 134: 492-497.

32. Fernandez-Fernandez R, Tena-Sempere M, Aguilar E, Pinilla L, 2004 Ghrelin effects on gonadotropin secretion in male and female rats. Neurosci Lett 362:103-107.

33. Tena-Sempere M, 2005 Exploring the role of ghrelin as novel regulator of gonadal function. Growth Horm IGF Res 15: 83-88.

34. I'Anson H, Quint EH, Wood RI, England BG, Foster DL, 1994 Adrenal axis and hypogonadotropism in the growth-restricted female lamb. Biol Reprod 50:137143.

35. Baptista T, Lacruz A, de Mendoza S, et al, 2000 Body weight gain after administration of antipsychotic drugs: correlation with leptin, insulin and reproductive hormones. Pharmacopsychiatry 33: 81-88.

36. Moshtaghi-Kashanian GR, Gholamhoseinian A, Hoseinimoghadam A, Rajabalian S, 2006 Splenectomy changes the pattern of cytokine production in beta-thalassemic patients. Cytokine 35: 253-257. 